\title{
Direito à saúde e judicialização no acesso a tratamentos de média e alta complexidade pelo Sistema Único de Saúde (SUS)
}

\author{
Right to health and judicialization in access to medium and high complexity treatments through the \\ Unique Health System (SUS) \\ Derecho a la salud y a la judicialización en el acceso a tratamientos de media y alta complejidad \\ mediante el Sistema Único de Salud (SUS)
}

Recebido: 18/02/2021 | Revisado: 26/02/2021 | Aceito: 03/03/2021 | Publicado: 10/03/2021

\author{
Mariana Lara \\ ORCID: https://orcid.org/0000-0002-3264-317X \\ Universidade Estadual Paulista "Júlio de Mesquita Filho", Brasil \\ E-mail: marianalara97@gmail.com \\ Clemente Maia da Silva Fernandes \\ ORCID: https://orcid.org/0000-0002-5401-6265 \\ Universidade Estadual Paulista "Júlio de Mesquita Filho", Brasil \\ E-mail: c.face@terra.com.br \\ Valéria Pavão Penteado \\ ORCID: https://orcid.org/0000-0003-4356-1396 \\ Universidade Estadual Paulista “Júlio de Mesquita Filho", Brasil \\ E-mail: valeriapvo@hotmail.com \\ Mônica da Costa Serra \\ ORCID: https://orcid.org/0000-0001-8820-2982 \\ Universidade Estadual Paulista “Júlio de Mesquita Filho", Brasil \\ E-mail: monica.serra@unesp.br
}

\begin{abstract}
Resumo
O presente artigo pauta-se na judicialização do acesso aos atendimentos de alta e média complexidade do Sistema Único de Saúde (SUS), assim consideradas as demandas judiciais movidas contra o SUS pedindo atendimentos que demandam alta densidade tecnológica e/ou exigência de expertise e habilidades especiais acima dos padrões médios, com baixa frequência relativa; e com alto custo unitário e/ ou do tratamento. Iniciado através de revisão bibliográfica, valendo-se de raciocínio indutivo, o trabalho desenvolvido busca expor a ineficiência e omissão do Sistema Único de Saúde pela apreciação de resultados de estudos referentes às demandas judiciais que tocam ao direito à saúde, considerando que a necessidade de intervenção judicial nesta matéria reflete a falha na via administrativa de cumprir com a proteção constitucional ao direito à saúde, fortemente positivada no ordenamento jurídico brasileiro, da Lei Maior às normas infraconstitucionais e atos administrativos dos órgãos que compõem o Sistema Único de Saúde, bem como, de forma complementar, na iniciativa privada.
\end{abstract}

Palavras-chave: Direito; Direito à saúde; Judicialização da saúde; Acesso aos serviços de saúde; Sistema Único de Saúde; Acesso efetivo aos serviços de Saúde; Bioética.

\begin{abstract}
This article is based on the judicialization of access to services of high and medium complexity of the Brazilian Unified Health System (SUS), thus considering the lawsuits filed against the SUS asking for services that demand high technological density and/or demand for expertise and special skills above average standards, with low relative frequency; and with high unit cost and / or treatment. Initiated through a bibliographic review, using inductive reasoning, the developed work seeks to expose the inefficiency and omission of the Unified Health System by assessing the results of studies referring to judicial demands that affect the right to health, considering that the need for intervention in this matter reflects the failure in the administrative way to comply with the constitutional protection of the right to health, strongly supported in the Brazilian legal system, from the Brazilian Constitution to the infraconstitutional rules and administrative acts of the organs that are part of the Unified Health System, as well as of complementary form, in the private initiative.
\end{abstract}

Keywords: Law; Right to health; Health's judicialization; Health services accessibility; Unified Health System; Effective access to health services; Bioethics. 


\section{Resumen}

Este artículo se fundamenta en la judicialización del acceso a servicios de alta y media complejidad del Sistema Único de Salud (SUS), considerando así las demandas interpuestas contra el SUS solicitando servicios que demandan alta densidad tecnológica y/o demanda de pericia y competencias especiales. estándares por encima del promedio, con baja frecuencia relativa; y con alto costo unitario y/o tratamiento. Iniciado a través de una revisión bibliográfica, mediante razonamiento inductivo, el trabajo desarrollado busca exponer la ineficiencia y omisión del Sistema Único de Salud mediante la evaluación de los resultados de estudios referentes a demandas judiciales que afectan el derecho a la salud, considerando que la necesidad de intervención en este asunto refleja el incumplimiento en la vía administrativa de la protección constitucional del derecho a la salud, fuertemente sustentada en el ordenamiento jurídico brasileño, desde la Ley Mayor hasta las normas infraconstitucionales y los actos administrativos de los órganos que integran el Sistema Único de Salud, así como de forma complementaria, en la iniciativa privada.

Palabras clave: Derecho; Derecho a la salud; Judicialización de la salud; Acceso a los servicios de salud; Sistema Único de Salud; Acceso efectivo a los servicios de salud; Bioética.

\section{Introdução}

No Brasil, hodiernamente, a questão da precariedade do SUS é pauta frequente de inúmeras discussões de cunho político, econômico e social, mas a apreciação de números judiciais referentes ao tema raramente é explorada ou levantada, motivo pelo qual o presente estudo busca indicar obras relevantes de introdução a essas questões e oferecer uma breve discussão sobre a questão da judicialização como indicadora da ineficiência e omissão do Poder Público no adequado atendimento às demandas da saúde pública.

O presente artigo desenvolve-se em torno da questão da judicialização do acesso aos atendimentos de alta e média complexidade do Sistema Único de Saúde (SUS) brasileiro, isto é, a crescente demanda nos Tribunais de decisões em matéria de acesso ao sistema público de saúde.

\section{Metodologia}

O presente artigo apresenta um estudo descritivo, do tipo teórico-reflexivo, realizado a partir da leitura de legislação referente ao Sistema Único de Saúde brasileiro, bem como estudos de casos de julgados de demandas envolvendo a judicialização do acesso ao atendimento pelo SUS e literatura sobre o tema, aproximando-se da abordagem qualitativa (Pereira et al., 2018).

\section{O Direito à Saúde e a Criação do Sistema Único de Saúde (SUS)}

O Brasil, até a promulgação da Constituição da República Federativa do Brasil (Brasil, 1988), não contava com disposições legais sólidas e organizadas sobre o direito à saúde. De fato, o Ministro Luís Roberto Barroso (Barroso, 2009) indica que foi com a redemocratização que a universalização dos serviços públicos de saúde, até então restritos ao trabalhador urbano contribuinte com carteira de trabalho assinada, passou a sem amplamente discutida.

Tal discussão culminou, em 1988, na criação do Sistema Único de Saúde pela Assembleia Constituinte (Lima \& Aguiar, 2020). No texto da Lei Maior, o direito à saúde ganhou status de garantia social fundamental, contando com previsão expressa no caput do Art. $6^{\circ}$ da Carta Magna, bem como tratado especialmente na Seção II do Capítulo II do "Título VIII - Da ordem social" da mesma norma.

O Art. 196 da Constituição Federal estabelece (Brasil, 1988):

Art. 196. A saúde é direito de todos e dever do Estado, garantido mediante políticas sociais e econômicas que visem à redução do risco de doença e de outros agravos e ao acesso universal e igualitário às ações e serviços para sua promoção, proteção e recuperação.

Por sua vez, o Art. 198 cria o Sistema Único de Saúde, como se vê: 
Art. 198. As ações e serviços públicos de saúde integram uma rede regionalizada e hierarquizada e constituem um sistema único, organizado de acordo com as seguintes diretrizes:

I - descentralização, com direção única em cada esfera de governo;

II - atendimento integral, com prioridade para as atividades preventivas, sem prejuízo dos serviços assistenciais;

III - participação da comunidade.

$\S 1^{\circ}$. O sistema único de saúde será financiado, nos termos do art. 195, com recursos do orçamento da seguridade social, da União, dos Estados, do Distrito Federal e dos Municípios, além de outras fontes.

$\S 2^{\circ}$ A União, os Estados, o Distrito Federal e os Municípios aplicarão, anualmente, em ações e serviços públicos de saúde recursos mínimos derivados da aplicação de percentuais calculados sobre:

I - no caso da União, a receita corrente líquida do respectivo exercício financeiro, não podendo ser inferior a $15 \%$ (quinze por cento);

II - no caso dos Estados e do Distrito Federal, o produto da arrecadação dos impostos a que se refere o art. 155 e dos recursos de que tratam os arts. 157 e 159, inciso I, alínea a, e inciso II, deduzidas as parcelas que forem transferidas aos respectivos Municípios;

III - no caso dos Municípios e do Distrito Federal, o produto da arrecadação dos impostos a que se refere o art. 156 e dos recursos de que tratam os arts. 158 e 159 , inciso I, alínea b e $\S 3^{\circ}$.

$\S 3^{\circ}$ Lei complementar, que será reavaliada pelo menos a cada cinco anos, estabelecerá:

I - os percentuais de que tratam os incisos II e III do $\S 2^{\circ}$;

II - os critérios de rateio dos recursos da União vinculados à saúde destinados aos Estados, ao Distrito Federal e aos Municípios, e dos Estados destinados a seus respectivos Municípios, objetivando a progressiva redução das disparidades regionais;

III - as normas de fiscalização, avaliação e controle das despesas com saúde nas esferas federal, estadual, distrital e municipal;

$\S 4^{\circ}$ Os gestores locais do sistema único de saúde poderão admitir agentes comunitários de saúde e agentes de combate às endemias por meio de processo seletivo público, de acordo com a natureza e complexidade de suas atribuições e requisitos específicos para sua atuação.

$\S 5^{\circ}$ Lei federal disporá sobre o regime jurídico, o piso salarial profissional nacional, as diretrizes para os Planos de Carreira e a regulamentação das atividades de agente comunitário de saúde e agente de combate às endemias, competindo à União, nos termos da lei, prestar assistência financeira complementar aos Estados, ao Distrito Federal e aos Municípios, para o cumprimento do referido piso salarial.

$\S 6^{\circ}$ Além das hipóteses previstas no $\S 1^{\circ}$ do art. 41 e no $\S 4^{\circ}$ do art. 169 da Constituição Federal, o servidor que exerça funções equivalentes às de agente comunitário de saúde ou de agente de combate às endemias poderá perder o cargo em caso de descumprimento dos requisitos específicos, fixados em lei, para o seu exercício.

É válido observar que a criação do Sistema Único de Saúde não objetivava tirar a liberdade da iniciativa privada em atuar na prestação de serviços à saúde do brasileiro. Pelo contrário, o Art. 199 da Constituição Federal (Brasil, 1988) expressamente autoriza a assistência à saúde pela iniciativa privada, de forma a complementar a atividade estatal na garantia de proteção à saúde da população. O que realmente se buscava era estabelecer um sistema de saúde público com atendimento universal, financiado e mantido por todos os entes federados (União, Estados, Distrito Federal, Municípios e territórios federais), com responsabilidade solidária, podendo a parte demandante optar pelo cumprimento da obrigação de um ou de todos, de acordo com artigo 23, inc.II, da CF. Assim sendo, ao ser indeferido o tratamento ou medicamento, na esfera administrativa, o demandante não tem outra alternativa que não seja apelar para o judiciário para o cumprimento do pleito dos seus direitos estabelecidos na Carta Magna.

A concorrência entre estes entes também se dá no plano legislativo, por força dos Arts. 24, inciso XII, e 30, inciso II, da CF/88, o que significa que as casas legislativas federais, estaduais (e distrital) e municipais estão todas aptas a, dentro de sua esfera de atuação, legislar sobre a matéria de saúde ${ }^{2}$, desde que observadas as exigências e parâmetros materiais e formais para tal.

Após a previsão constitucional, foi sancionada a Lei no 8.080, de 19 de setembro de 1990 (Brasil, 1990), para, citando seu Art. 1 10, "[regular], em todo o território nacional, as ações e serviços de saúde, executados isolada ou conjuntamente, em caráter permanente ou eventual, por pessoas naturais ou jurídicas de direito Público ou privado".

Vale citar que algumas matérias não cuidadas em lei acabam sendo reguladas por normas internas e atos administrativos, como é o caso dos critérios de repartição das competências para fornecimento de medicamentos, que é regulada por inúmeras 
normas, sendo a principal a Portaria n 3.916/98, do Ministério da Saúde, instituidora da "Política Nacional de Medicamentos" (Brasil, 1998).

Com a Lei 8.080/90, que ganhou o nome de "Lei Orgânica da Saúde" (Brasil, 1990), estava regulada a criação do Sistema Único de Saúde (SUS) e de seus órgãos principais. Em seu artigo $6^{\circ}$, estão incluídas ainda no campo de atuação do SUS:

I - A execução de ações:

a) de vigilância sanitária;

b) de vigilância epidemiológica;

c) de saúde do trabalhador;

d) de assistência terapêutica integral, inclusive farmacêutica (grifo nosso)

Desde que a Lei Orgânica da Saúde foi aprovada, um grande número de normas foi editado, cuidando de matérias como o mínimo de recursos que cada ente federado deve destinar à manutenção do SUS (Lei complementar ${ }^{\circ} 141$, de 13 de janeiro de 2012) ou a forma da participação da comunidade na gestão do SUS e sobre as transferências intergovernamentais de recursos financeiros na área da saúde (Lei no 8.142, de 28 de dezembro de 1990).

No entanto, para a Lei 8.080/90 ter maior eficácia, foi modificada pela Lei 12.401, de 28 de abril de 2011 (Brasil, 2011), que acrescentou, sob o Título II, o Capítulo VIII - Da Assistência Terapêutica e Da Incorporação De Tecnologia Em Saúde, dando maior abrangência aos serviços prestados pelo SUS (artigo 19-M), incluindo, por exemplo, oferta de procedimentos terapêuticos, em regime domiciliar. São vedados o ressarcimento, pagamento ou reembolso de medicamento, produtos procedimento clínico ou cirúrgico experimental, ou de uso não autorizado ou não registrado na Agência Nacional de Vigilância Sanitária - ANVISA.

Além disso, a Lei 12.401/11 definiu protocolo clínico (artigo 19-N) estabelecendo critérios para dispensação de medicamentos e produtos de interesse para saúde, orientando a descrição prescrição do tratamento recomendado, produtos necessários, posologia, mecanismos de controle clínico e aconselhamento e verificação dos resultados terapêuticos exigidos pelos expertises do SUS.

Assim, percebe-se que a intenção da regulamentação da Lei do SUS veio ao encontro da fiscalização do direto já estabelecido por lei na Constituição Federal. As discussões suscitadas nos levam a entender que tais normas, propostas pelo legislador, norteiam a tomada de decisão, deixando forte a impressão de que foram normas criadas para respaldo do judiciário.

Nesse sentido, é claro o artigo 19-Q in verbis:

A incorporação, a exclusão ou a alteração pelo SUS de novos medicamentos, produtos e procedimentos, bem como a constituição ou a alteração de protocolo clínico ou de diretriz terapêutica, são atribuições do Ministério da Saúde, assessorado pela Comissão Nacional de Incorporação de Tecnologias no SUS.

A título ilustrativo, citamos a Medida Cautelar na Suspensão de Tutela Provisória: stp 0101599-92.2020.1.00.0000 MG (Supremo Tribunal Federal, 2020), onde o município alega não ter competência para arcar com os custos do tratamento, por isso recorre ao STF pleiteando a suspensão dos efeitos da tutela antecipada concedida pelo juízo de $1^{\circ}$ grau e mantida nos Autos do Agravo de Instrumento $n^{\circ}$ 900039-09.2020.8.13.0525. Neste caso, na origem foi ajuizada ação de obrigação de fazer, com pedido de liminar, pleiteando o fornecimento dos medicamentos diosmin, forxiga 10mg e januvia. Inconformado com a decisão de acolhimento da pretensão, o Município apresentou pedido de suspensão da tutela antecipada ao STF alegando grave lesão à ordem, à saúde e à economia, sustentando que a obrigação quanto ao fornecimento de medicamentos sem registro na ANVISA deve recair na União.

Assim, compete à autoridade judiciária direcionar o cumprimento das regras. Apesar da Constituição Federal firmar a 
responsabilidade solidária entre os entes da federação, os ministros divergem em sua interpretação, por se preocuparem, por um lado com a descentralização e hierarquização em atenção aos critérios constitucionais e pelo outro lado, com as regras de repartição de competência do SUS, suscitando o dever do judiciário direcionar a complexa divergência.

Desta forma, em toda e qualquer mudança no protocolo orientador especificado pelo artigo 19-N da Lei 8.080/90, a competência passa a ser do Ministério da Saúde, esvaziando a competência de decisão estadual e municipal, passando para o ente federativo.

Pode-se inferir, então, que o legislador propôs o Projeto de Lei, na iminência da judicialização.

\section{As Dificuldades do Acesso aos Procedimentos de Média e Alta Complexidade pelo SUS}

Apesar de três décadas terem se passado desde a criação do SUS, o sistema de saúde público organizado e eficiente que se idealizou está longe de concretizar-se. Entre polêmicas, os desvios de verbas, a má gestão orçamentária dos chefes dos três poderes e falhas na prestação adequada e em tempo razoável do serviço de saúde aos cidadãos, um dos maiores desafios que permeia o Sistema Único de Saúde é a própria dificuldade que o sistema impõe ao acesso aos procedimentos de média e alta complexidade. Alegando o ente demandado que o problema está no orçamento anual, violando assim, o princípio da proibição de retrocesso social. (Lewandowski, 2018).

Um exemplo claro deste cenário está exibido no trabalho coordenado por Sómon Magalhães Vianna (Vianna et al., 2005), em que se apurou diversos números relativos aos atendimentos de alta complexidade realizados pelo SUS entre 1993 e 2003 e os sintetizou, definindo conceitos como atendimento de alta complexidade sendo aquele que demanda alta densidade tecnológica e/ou exigência de expertise e habilidades especiais acima dos padrões médios, com baixa frequência relativa; e com alto custo unitário e/ ou do tratamento. Os autores do trabalho notam que sempre haverá divergências e exceções a tais critérios, mas partindo daí é possível se identificar quais atendimentos são mais onerosos e difíceis de serem prestados.

Os atendimentos de média complexidade, evidentemente, seriam aqueles que se encaixam parcialmente ou de forma atenuada nos critérios enumerados acima.

Ante seu alto custo e demanda altamente especializada, tais atendimentos dificilmente seriam suportáveis para o cidadão médio brasileiro, de forma que, sendo necessários, resta ao paciente buscar apoio do sistema público de saúde para prestação desses atendimentos. Contudo, falível e imperfeito como ainda é o SUS, muitas vezes esse atendimento é negado ou está indisponível, de forma que o paciente fica obrigado a buscar a intervenção do Poder Judiciário para obter o adequado atendimento à sua condição (Ventura et al. 2010), correndo o risco de ter a tese do pleito negada, pois consoante ao STJ, Recurso Especial Repetitivo 1657.156, relatado pelo Ministro Benedito Gonçalves, em 25/04/2018 (Superior Tribunal de Justiça, 2018), alguns critérios passaram a ser exigidos para a concessão de medicamentos não constantes na lista do SUS, tais como:

1 - Comprovação, por meio de laudo médico fundamentado e circunstanciado expedido por médico que assiste o paciente, da imprescindibilidade ou necessidade do medicamento, assim como da ineficácia, para o tratamento da moléstia, dos fármacos fornecidos pelo SUS;

2 - Incapacidade financeira do paciente de arcar com o custo do medicamento prescrito; e

3 - Existência de registro do medicamento na Agência Nacional de Vigilância Sanitária (Anvisa).

Como se vê, o paciente é compelido a exagerados trâmites burocráticos para comprovar a necessidade de fazer uso de determinada medicação ou prestação de serviço especializado, assim como comprovar a hipossuficiência econômica para ter o benefício do Estado. 


\section{O Fenômeno da "Judicialização" no Acesso ao Atendimento pelo SUS}

Exposto o que é o direito à saúde e como se criou o Sistema Único de Saúde (SUS) e exposto o cenário da dificuldade de acesso aos atendimentos de alta e média complexidade pelo mencionado sistema, passa à exposição do fenômeno da “judicialização", termo definido pela decisão, pelo Judiciário, de questões relevantes do ponto de vista político, social ou moral (Gomes et al., 2014; Ramos et al., 2016; Pereira Netto et al., 2017; Domingues et al., 2017).

Como mencionado, o SUS ainda mostra deficiências e falhas que muitas vezes pressionam o paciente necessitado de atendimentos de maior complexidade a recorrer à via judicial para obter seu adequado tratamento. Como Ventura et al. (2010) expõem:

Os trabalhos empíricos apontam que a demanda judicial brasileira mais recorrente no âmbito da saúde é constituída por pedidos - individuais e coletivos - de medicamentos. Os pedidos judiciais se respaldam numa prescrição médica e na suposta urgência de obter aquele insumo, ou de realizar um exame diagnóstico ou procedimento, considerados capazes de solucionar determinada "necessidade" ou "problema de saúde". A escolha da via judicial para o pedido pode ser dar pela pressão para a incorporação do medicamento/procedimento no SUS ou pela ausência ou deficiência da prestação estatal na rede de serviços públicos.

Citando o exemplo dos resultados de Gomes et al. (2014), que em seu estudo analisou 6.112 (seis mil cento e doze) processos judiciais referentes a medicamentos, materiais, equipamentos, procedimentos e outros pedidos relacionados à saúde, movidos contra o Estado de Minas Gerais entre 1999 e 2009, que mostram a ineficiência e a omissão do mencionado Estado nos atendimentos de média e alta complexidade:

$\mathrm{Na}$ classificação dos procedimentos por modalidade, foram agrupadas todas as designações contendo "hospitalar", totalizando $77 \%$. Predominaram os procedimentos de média complexidade $(51,1 \%)$ e os de alta complexidade $(44,4 \%)$. Observou-se que $80,8 \%$ dos procedimentos clínicos eram de média complexidade, e $53,6 \%$ dos procedimentos cirúrgicos eram de alta complexidade $(53,6 \%)$. Apesar de não ter sido utilizada nenhuma referência para identificação da complexidade dos demais procedimentos, percebe-se que houve predomínio de solicitações de internação, internação em CTI, procedimentos cirúrgicos e exames com tecnologia avançada, que poderiam ser denominados como de média ou alta complexidade.

Este cenário não se limita ao Estado mineiro - a alta demanda judicial pelo acesso aos serviços do sistema público de saúde é uma realidade nacional, com variações nos números conforme cada região, mas que expõem a triste situação da precariedade da saúde pública brasileira.

\section{Considerações Finais}

Por todo o exposto, verifica-se que o legislador nacional, nas últimas três décadas, busca criar uma sólida atuação do Poder Público na garantia e proteção do direito à saúde do cidadão brasileiro.

Esta iniciativa, contudo, não se reflete na realidade, em que o Sistema Único de Saúde, embora conte com ampla legislação estimulando seu fomento e manutenção, ainda se mostra incapaz de atender à demanda da população, especialmente nos atendimentos que exigem habilidades técnicas, recursos, equipamentos, materiais de qualidade acima da média e custo significativo, denominados de "alta e média complexidade".

Neste cenário, a judicialização surge como a interferência do Judiciário na relação entre o SUS e o paciente a fim de decidir e garantir a prestação do atendimento adequado, dentro da capacidade do SUS e observado o grau de necessidade do paciente.

Todavia, a via judicial não garante a satisfação do autor (no caso, paciente), em todos os processos instalados pois, como visto, é necessária a comprovação da real necessidade do tratamento e medicamento, assim como a comprovação da 
hipossuficiência econômica.

Os resultados dos estudos revisados mostram que grande parte dessas demandas judiciais concentra atendimentos de alta e média complexidade, o que expõe a falha do SUS em cumprir seu papel em relação a esses pacientes.

Propõe-se a realização de mais estudos qualitativos sobre os cenários, a fim de apurar quais espécies de atendimentos de alta e média complexidade figuram em maior número dentre os pedidos demandados judicialmente, para que assim se apure em que áreas importantes do atendimento à saúde popular o Sistema Único de Saúde se mostra menos eficiente e, a partir desses resultados, se desenvolva modelos capazes de melhor cumprir as garantias constitucionais à saúde do brasileiro.

\section{Referências}

Brasil. (1988) Constituição da República Federativa do Brasil de 1988. http://www.planalto.gov.br/ccivil_03/constituicao/constituicao.htm.

Brasil. (1990). Lei $n^{\circ} 8.142$, de 28 de dezembro de 1990: Dispõe sobre a participação da comunidade na gestão do SUS e sobre as transferências intergovernamentais de recursos financeiros na área da saúde e dá outras providências. http://www.planalto.gov.br/ccivil_03/leis/18080.htm

Brasil. (2011) Lei ${ }^{\circ} 12.401$, de 28 de abril de 2011. Altera a Lei nº 8.080, de 19 de setembro de 1990, para dispor sobre a assistência terapêutica e a incorporação de tecnologia em saúde no âmbito do Sistema Único de Saúde - SUS. http://www.planalto.gov.br/ccivil_03/_ato2011-2014/2011/lei/112401.htm

Brasil (1998) Ministério da Saúde. Portaria $\mathrm{n}^{\circ}$ 3.916, de 30 de outubro de 1998 . http://bvsms.saude.gov.br/bvs/saudelegi s/gm/1998/prt3916_30_10_1998.html\#: :text=Contempla\%20diretrizes\%20e\%20define\%20prioridades,e\%20desenvolvimento\%20cient\%C3\%ADfico\%20e

$\% 20$ tecnol\% C3\%B3gico.

Barroso, L. R. (2009). Da falta de efetividade à judicialização excessiva: direito à saúde, fornecimento gratuito de medicamentos e parâmetros para a atuação judicial. https://www.conjur.com.br/dl/estudobarroso.pdf

Domingues, L. F. P., Lisbôa, T. S., Souza Neto, R. C., Elias, P. G., Souza, L. A. \& Perire, M. D. (2017) Análise das demandas judiciais de saúde no Departamento Regional XII -Registro/SP. Research, Society and Development, 5(4): 276-289.

Gomes, F. D. F. C., Cherchiglia, M. L., Machado, C. D., Santos, V. C. D., Acurcio, F. D. A., \& Andrade, E. I. G. (2014). Acesso aos procedimentos de média e alta complexidade no Sistema Único de Saúde: uma questão de judicialização. Cadernos de Saúde Pública, 30, 31-43.

Lewandowski, R. (2018) Proibição do retrocesso. http://www.stf.jus.br/arquivo/biblioteca/PastasMinistros/RicardoLewandowski/ArtigosJornais/1117223.pdf

Lima, C. S. \& Aguiar, R. S. (2020) Acesso dos homens aos serviços de atenção primária à saúde: uma revisão integrativa. Research, Society and Development, 9(4): e157943027.

Pereira, A. S., Shitsuka, D. M., Parreira, F. J. \& Shitsuka, R. (2018). Metodologia da pesquisa científica. [e-book]. Santa Maria. Ed. UAB/NTE/UFSM. https://repositorio.ufsm.br/bitstream/handle/1/15824/Lic_Computacao_Metodologia-Pesquisa-Cientifica.pdf?sequence=1

Pereira Netto, E., S., Lima, J.S., Souza Neto, R., C., Armesto, C., Souza, L. A. \& Pereira, M. D. (2017) Caracterização das demandas judiciais de saúde no município de Registro/SP. Research, Society and Development, 5(2): 157-170.

Ramos, R. S., Gomes, A. M. T., Oliveira, D. C., Marques, S. C., Spindola, T. \&, Nogueira, V. P.F. (2016) O acesso às ações e serviços do Sistema Único de Saúde na perspectiva da judicialização. Rev. Latino-Am. Enfermagem. 24:e2797.

Superior Tribunal de Justiça (2018). Recurso Especial: REsp 0015099-09.2014.8.19.036 RJ/20170025629-7. Recurso Especial n. 1.657.156-RJ. https://stj.jusbrasil.com.br/jurisprudencia/574252474/recurso-especial-resp-1657156-rj-2017-0025629-7/inteiro-teor-574252509

Supremo Tribunal Federal (2020) Medida Cautelar na Suspensão de Tutela Provisória: STP 0101599-92.2020.1.00.0000 - MG. https://stf.jusbrasil.com.br/jurisprudencia/1100946352/medida-cautelar-na-suspensao-de-tutela-provisoria-stp-639-mg-0101599-9220201000000/inteiro-teor1100946364

Ventura, M., Simas, L., Pepe, V. L. E., \& Schramm, F. R. (2010). Judicialização da saúde, acesso à justiça e a efetividade do direito à saúde. Physis: Revista de Saúde Coletiva, 20(1), 77-100. https://doi.org/10.1590/S0103-73312010000100006

Vianna, S. M., Nunes, A., Góes, G., Silva, J. D., \& Santos, R. J. M. (2005). Atenção de alta complexidade no SUS: desigualdades no acesso e no financiamento. Projeto economia da saúde. Brasília: Ministério da Saúde/Instituto de Pesquisa Econômica Aplicada. http://bvsms.saude.gov.br/bvs/publicacoes/ipea_alta_complexidade.pdf 